\title{
Effect of Air Abrasion and Different Silicoating Techniques on the Bond Strength of Particulate Filler Composite to Titanium
}

\section{Cengiz S1*, Külünk Ş², Yüzbaşıoğlu HE², Velioğlu N1 and Külünk T² \\ ${ }^{1}$ Department of Prosthodontics, Faculty of Dentistry, Bülent Ecevit University, Turkey \\ ${ }^{2}$ Department of Prosthodontics, Faculty of Dentistry, Ondokuz Mayıs University, Turkey \\ ${ }^{3}$ Department of Prosthodontics, Faculty of Dentistry, Medipol University, Turkey}

*Corresponding author: Seda Cengiz, Department of Prosthodontics, Faculty of Dentistry, Bülent Ecevit University, Turkey, E-mail: sedabc@hotmail.com

\section{Research Article \\ Volume 2 Issue 3}

Received Date: March 10, 2017

Published Date: August 03, 2017

DOI: $10.23880 /$ oajds-16000139

\section{Abstract}

Background/purpose: One of the problems associated with titanium metal-composite restorations is insufficient ability to bond resin to titanium metal castings. The purpose of this study was to evaluate the effect of two different silicacoating techniques and air abrasion with different particles on the bond strength of a particulate filler composite to titanium alloy.

Materials and Methods: 40 titanium bar specimens divided in 5 groups were air abraded with $50 \mu \mathrm{m}$ aluminum oxide (Al203) particles (Group C); air abraded with Al203 and then flamed with the Silano-Pen device (Bredent, Germany) (Group CSP); air abraded with silica-coated aluminum oxide particles (Group S); air abraded with synthetic diamond abrasives (Group D); and air abraded with diamond abrasives and flamed with the Silano-Pen device (Group DSP). The composite resin build-up was fabricated according to the manufacturer's recommendations. Shear bond strength of resin composite to the titanium surface were evaluated after $24 \mathrm{~h}$ storage in water at $37^{\circ} \mathrm{C}$.

Results: Data were analyzed by one-way analysis of variance (ANOVA), and the mean values were compared by post-hoc Tukey compromise test $(p=0.05)$. The SEM photomicrographs were developed at a magnification of $\times 500$ for visual inspection. To assess the mode of failure (cohesive, adhesive or mixed failure) the specimen surfaces were examined. There was no significant difference in bond strength values of group $C$ and the other surface treated groups. ( $>0.05)$. Application of Silano-Pen increased shear bond strength in treated with only synthetic diamond abrasives group. Group CSP showed higher bond strength than group S and D. Group DSP showed higher bond strength than group D, too.

Conclusion: Although Silano-Pen application after air abrasion with synthetic diamond abrasives effected the bond strength of titanium to composite, there was not any difference from only air abraded surface treatment.

Keywords: Silicoating; Titanium; Particulate filler composite 


\section{Open Access Journal of Dental Sciences}

\section{Introduction}

The development of new processing methods- such as lost-wax casting, computer-aided machining and electric discharge machining- has allowed the use of pure titanium and its alloys for dental implants, surgical splints, stents and fasteners, partial denture frameworks, fixed partial dentures and root posts [1-9]. Although various metal alloy can be used to fabricate fixed partial dentures, titanium presents several advantages as a prosthetic material, such as excellent biocompatibility, good mechanical properties, high corrosion resistance, low density and low cost compared to noble metals [211]. However, problems with porcelain bonding have been reported when titanium is used in metal-ceramic restorations as thick and non-adherent layers of titanium oxide are formed. The presence of an excessive oxide layer is a possible cause of decreased bonding durability. For this reason, particulate filler composite resin materials used on titanium castings as an alternative to porcelain fused to metal restorations for esthetic anterior/posterior restorations [9-12]. Indirect lightcured composite resins have been extensively used in tooth restoration because they can provide acceptable aesthetics, wear resistance similar to tooth structure, and are easy to manipulate in the laboratory and to repair $[3,8,9]$. However, one of the problems associated with titanium metal-composite restorations is insufficient ability to bond resin to titanium metal castings. The deficient bonding of indirect composites to the metallic alloys could promote the formation of marginal gaps and causing weak bond strength $[2,3,6,8,9]$. Like other metal alloys, use of titanium alloy for fixed partial denture requires a strong and stable bond between metal and esthetic veneering material (porcelain or composite resin) or metal and resin cement $[11,13]$.

Several systems including chemical and mechanical surface treatment methods have been developed in order to improve the bond strength of resin materials to titanium. Macro-(mesh, beads, rough surface with particles) or micro-mechanical treatments (air-abrasion with alumina particles, electrolytic etching, porous metal coating, and acid etching), chemical treatments (4-META composites, phosphate-based composites) and adhesive layer application (tin plating, titanate coupler, silane coupling, carboxylic monomers, a phosphate monomer) were the only mechanisms for bonding composite materials to metallic substrates $[2,3,6-9,14]$.

Other systems involve treatment of titanium surface to render it more reactive to bonding agents either by coating the metal surface with silicate (enabling bonding through a silane coupling agent or laser welded), conditioning the metal surface with organic acids in solvents, embedded in methacrylate-based liquids and polydimethylsiloxane coating that bond to the titanium oxides and to the resin composites [7-10,15]. Airborneparticle abrasion with aluminum oxide particles is commonly used for to clean the surfaces by removal of metal oxide or debris, to clinical fit of restoration and to increase micro- mechanical roughening and physicochemical changes which affect surface energy and wettability of the surface retention $[6,9]$.

In dentistry, one alternative air abrasion material is synthetic diamond particles. It was previously applied onto the glass-infiltrated aluminous oxide ceramic surface to increase the surface roughness and surface area $[16,17]$ then it was used on zirconia core, $\mathrm{Ni}-\mathrm{Cr}$ and $\mathrm{Co}-\mathrm{Cr}$ surface [18,19]. Several studies have shown that silicoating and functional monomer systems improve the composite-to-metal bond strength with noble and nonnoble dental alloys and with titanium and its alloys $[2,8,11,19]$. The aim of this study was to evaluate the effect of two different silica-coating techniques and air abrasion with different particles on the bond strength of a particulate filler composite to commercially pure titanium alloy. The research hypothesis tested was that the shear bond strength would increase after application of alternative surface treatment methods.

\section{Material and Methods}

The materials used in this study were presented in (Table 1). Titanium bars of commercially pure titanium (Grade 2, Bağsan Tic. A.Ş., Turkey) were sectioned with a lathe (Hawk TC-150, Cincinati Machine Ltd. Co., UK) and 40 square-shaped specimens $(10 \times 10 \mathrm{~mm}, 2 \mathrm{~mm}$ in thickness) were obtained. All specimens were embedded in the centers of autopolymerizing acrylic resin blocks (Meliodent; Heraeus Kulzer, Armonk, NY). Then the surface of each specimen was ground with a series of silicon carbide papers (280-, 400-, 600-, 800- and 1000grit) (3M ESPE, St. Paul, USA) for $10 \mathrm{sec}$ on a $300 \mathrm{rpm}$ grinding machine (Buehler Metaserv, Buehler, Germany) under running water in order to provide flat and uniform surface and ultrasonically cleaned for $3 \mathrm{~min}$ deionized water and air-dried. All specimens were divided 5 groups, each containing 8 specimens. The specimens in the groups were air abraded with $50 \mu \mathrm{m}$ aluminum oxide (Al2O3) particles (Group C); air abraded with $50 \mu \mathrm{m}$ aluminum oxide (Al203) particles and then flamed with the SilanoPen device (Bredent GmbH, Senden, Germany) (Group 


\section{Open Access Journal of Dental Sciences}

CSP) for $5 \mathrm{~s} / \mathrm{cm} 2$; air abraded with $30 \mu \mathrm{m}$ silica-coated aluminum oxide particles $\left(\mathrm{SiO}_{\mathrm{x}}\right)$ and application of a thin silane layer (Espe-Sil, 3M ESPE), which was left to dry for 5 minutes (Group S); air abraded with 30-50 $\mu$ m synthetic diamond abrasives (Group D); and air abraded with 30-50 $\mu \mathrm{m}$ synthetic diamond abrasives and then flamed with the Silano-Pen device (Group DSP) for $5 \mathrm{~s} / \mathrm{cm} 2$. After specimens were flamed with Silano-Pen device, specimens were cooling down to room temperature and then the Silano-Pen bonding agent was brushed on and air-dried for $3 \mathrm{~min}$. Air abrasion procedure was performed using an intraoral air abrasion device (Microetcher, Danville Engineering Inc, San Ramon, Calif, USA) at an air pressure of 2.5 bars for $10 \mathrm{sec}$ at a distance of approx. $10 \mathrm{~mm}$.

\begin{tabular}{|c|c|c|}
\hline Material & Composition & Manufacturer \\
\hline Signum Metal Bond I+II & $\begin{array}{c}\text { Inorganic pigments, } \mathrm{SiO}_{2} \text {, methyl methacrylate, } \\
\text { acetone }\end{array}$ & Heraeus Kulzer, Hanau, Germany \\
\hline Signum Composite & Bis-GMA and TEGDMA - $\mathrm{SiO}_{2}$, & Heraeus Kulzer, Hanau, Germany \\
\cline { 2 - 3 } Silano-Pen & $\begin{array}{c}\text { alcoholic solution of 3- } \\
\text { methacryloyloxypropyltrimethoxy silane (MPS), } \\
\text { Ethanol }\end{array}$ & Bredent, Senden, Germany \\
\hline CoJet & $30 \mu \mathrm{m}$ silica-coated $\mathrm{Al}_{2} \mathrm{O}_{3}$ particles & 3M ESPE, Seefeld, Germany \\
\hline Korox® 50 & $99.6 \% 110 \mu \mathrm{ml}_{2} \mathrm{O}_{3}$ & BEGO, Bremen, Germany \\
\hline Micron+MDA M3050 & $30-50 \mu \mathrm{m}$ synthetic diamond particles & Elementsix, Shannon, Ireland \\
\hline
\end{tabular}

Table 1: Materials used for this study.

After surface treatments a thin layer metal bond (Signum Metal Bond I) was applied onto the all specimens surface and wait 15 seconds for it evaporate then a thin layer metal bond (Signum Metal Bond II) was applied onto the all specimens surfaces and then polymerized 90 seconds with a high performance light curing unit that has $300 \mathrm{~W}$ power input (Heraflash, Heraeuz Kulzer, Hanau, Germany). A teflon mold ( $2 \mathrm{~mm}$ thick) with a circular hole (6 $\mathrm{mm}$ in diameter) was positioned on the center of the specimens' surfaces. Composite resin (Signum Composite, DA2) build-up was completed by applying small increments according to the manufacturer's recommendation and polymerized 90 seconds in a lightcuring unit (Heraflash). The specimens were stored for 24 $\mathrm{h}$ in distilled water at $37{ }^{\circ} \mathrm{C}$. Shear bond strength of an indirect composite on the titanium surface after different surface treatment were evaluated after $24 \mathrm{~h}$ storage in water at $37^{\circ} \mathrm{C}$. Shear bond strength was then determined using a universal testing machine (Lloyd LRX; Lloyd Instruments, Fareham, Hampshire, UK) at a cross-head speed of $1 \mathrm{~mm} /$ minute where shearing load was applied parallel to the bonded interface. The means and standard deviations of 40 specimens were calculated for each group. The Kolmogorov-Simirnov test showed that the data had a normal distribution ( $\mathrm{P}>0.05)$. A homogeneity of variance test was done using Levene's test ( $\mathrm{F}$ ratio: $1.288, \mathrm{P}>0.05$ ). Data were analyzed by one-way analysis of variance (ANOVA), and the mean values were compared by post-hoc Tukey compromise test $(p=0.05)$ following one-way ANOVA. Titanium specimens submitted to five surface treatments including a control were selected for microphotographic evaluation. All specimens were examined under a field-emission scanning electron microscope (JSM-6335F; JEOL, Tokyo, Japan) at $10 \mathrm{kV}$. The SEM photomicrographs were developed at a magnification of $\times 500$ for visual inspection. To assess the mode of failure (cohesive, adhesive or mixed failure) the specimen surfaces were examined under stereomicroscope (Leica EZ4 D, Germany).

\section{Results}

The means and standard deviations (SD) of the shear bond strength values are presented in (Table 2). Result of one-way ANOVA showed that surface treatments effected shear bond strength between groups $(p<0.001)$ (Table 2). There was no significant difference in bond strength values of group $C$ and the other surface treated groups. $(\mathrm{p}>0.05)$. Application of Silano-Pen increased shear bond strength in treated with only synthetic diamond abrasives group. Group CSP showed higher bond strength than group S and D. Group DSP showed higher bond strength than group D, too. Stereomiscroscopic examination of the fractured surfaces showed that mixed fractures were most common types of failure for all groups. Pure composite resin cohesive failures were not observed. The specimens in Group C, S and CSP exhibited 100\% mixed 
failures. Group D showed 25\% and Group DSP showed $12.5 \%$ adhesive failure between alloy and composite resin. SEM photomicrographs of titanium alloy surfaces after different surface treatments are presented in (Figure 1). The topographic patterns differed between the specimens. The SEM photographs showed the control group had an irregular surface (a). The application of the sandblasting procedure with silano-pen did not change the surface topography of titanium alloy surface from the control group (b). The application of air abrasion with 30 $\mu \mathrm{m}$ silica-coated aluminum oxide particles ( $\mathrm{SiOx}$ ) and application of a thin silane layer filled the surface irregularities but not changed the surface texture (c). The application of air abrasion with 30-50 $\mu \mathrm{m}$ synthetic diamond abrasives filled the deep surface irregularities (d). The application of air abrasion with 30-50 $\mu \mathrm{m}$ synthetic diamond abrasives and then flamed with the Silano-Pen device created a more irregular and rough surface than the synthetic diamond abrasive application alone (e).

\begin{tabular}{|c|c|c|}
\hline Groups & Surface treatment & Mean \pm SD \\
\hline C (Control) & Air abrasion with $50 \mu \mathrm{Al}_{2} \mathrm{O}_{3}$ & $14.63 \pm 2.27 \mathrm{abc}$ \\
\hline CSP & $\begin{array}{c}\text { Air abrasion with } 50 \mu \mathrm{m} \\
\mathrm{Al}_{2} \mathrm{O}_{3}+\mathrm{Silano}-\mathrm{Pen}\end{array}$ & $16.82 \pm 1.40 \mathrm{c}$ \\
\hline S & Air abrasion with $30 \mu \mathrm{m} \mathrm{SiO}_{\mathrm{x}}$ & $13.83 \pm 1.24 \mathrm{ab}$ \\
\hline D & $\begin{array}{c}\text { Air abrasion with } 30-50 \mu \mathrm{m} \\
\text { synthetic diamond abrasives }\end{array}$ & $12.06 \pm 1.77 \mathrm{a}$ \\
\hline DSP & $\begin{array}{c}\text { Air abrasion with } 30-50 \mu \mathrm{m} \\
\text { synthetic diamond abrasives+ } \\
\text { Silano-Pen }\end{array}$ & $16.45 \pm 2.22 \mathrm{bc}$ \\
\hline
\end{tabular}

Table 2: Mean (MPa) and Standard Deviation (SD) values of shear bond strength.

\section{Discussion}

The bond strength between metal surface and esthetic restorative material (composite or porcelain) was effected by multiple factors such as thermal condition, chewing stimulus, features and characterization of esthetic material and metal [10]. This study set out to evaluate the influence of various surface conditioning methods on improving bond strength. Bonding with a composite resin and the oxide film of a metal is hydrophilic bond and this hydrophilic interface attracts water. The bond strength between alloy and composite depends on the dipole-dipole interactions, but the bond between metal and composite will be weakened through hydrolysis, and then might fail. Silicoating systems and functional monomer are used to reduce the hydrophilic character of the surface [10]. Silicoating systems cover the metal surface with thin layer of silica by the way tribochemical or pyrolytical methods. In the present study a pyrolytical method Silano-Pen was used (Table 3).

\begin{tabular}{|c|c|c|c|c|c|}
\hline & $\begin{array}{c}\text { Sum of } \\
\text { Squares }\end{array}$ & df & $\begin{array}{c}\text { Mean } \\
\text { Square }\end{array}$ & F & Sig. \\
\hline $\begin{array}{c}\text { Between } \\
\text { Groups }\end{array}$ & 122.11 & 4 & 30.53 & 9.12 & 0.001 \\
\hline $\begin{array}{c}\text { Within } \\
\text { Groups }\end{array}$ & 117.14 & 35 & 3.35 & & \\
\hline Total & 239.26 & 39 & & & \\
\hline
\end{tabular}

Table 3: One-way ANOVA results.

Air abrasion affects the bond strength of resins to titanium alloys, because airborne particle abrasion removes not only the impurities on the surface of titanium, but also the oxide films formed on the surface contaminated with aluminum oxides influencing the formation of the new oxide film, moreover sandblasting allows the remaining aluminum particles to chemically bond to resins [6,9,11]. Galo, et al. [9] stated that increasing of grid size of Al2O3 (50 to $250 \mu \mathrm{m}$ ) particles increased shear bond strength of indirect composite resin to titanium alloy [9]. It was evaluated silicoating and a functional monomer application on the bond strength of grade 1 titanium surface showed that they were not statistically affect the shear bond strength to titanium alloy and thermal cycle procedure reduced the bond strength in all groups [10]. Similarly, in the present study silicoating did not statistically affect the shear bond strength to titanium alloy. The Mohs hardness of titanium, silicon dioxide, aluminum oxide and synthetic diamond are 6, 6.5, 9 and 10, respectively [20]. Hardness of abrasive material did not affect the bond strength [18]. The lowest shear bond strength value was obtained with group D. Sandblasting with synthetic diamond abrasive might fill the deep surface irregularities on titanium alloy surface. With the application of silicoating, lower bond strength values were obtained when compared air abraded and Silano-Pen applied surfaces. Silano-Pen application after air abrasion procedures increased shear bond strength but no significant difference was found between group C, CSP and DSP ( $p>0.05)$. In a study which was evaluated the effect of three different surface treatment and luting agents on shear bond strength to titanium alloy showed that alkaline-heat treatment showed the highest bond strength values when compared other surface treatment [7]. In a previous study Yanagida, et al. [2] showed that higher shear bond strength values were obtained with primer and Siloc System [2]. Siloc System is based on the principle of burning of silica on a 


\section{Open Access Journal of Dental Sciences}

metallic alloy. Similar to Siloc System Silano-Pen system uses heat treatment on metal surface. In this study higher shear bond strength values were obtained with group CSP and DSP than group S and group D respectively. Silane coupling with heat treatment may be effective on titanium surface to increase shear bond strength [20]. When compared traditional surface treatment methods, with this system more favorable results were obtained in adhesive prostheses, metal-composite fixed partial denture and crowns, telescopic crowns and removable partial dentures [12]. But when compared the Siloc system, silano-pen application is useful and easy handling in clinical and laboratory condition. Air abrasion with only synthetic diamond abrasive applied group showed lower bond strength values than groups with Silano-Pen was used significantly. This can be attributed to the effectiveness of heat treatment on the bond strength of titanium alloy and filler particulate composite. Also air abrasion with synthetic diamond abrasive applied groups showed only adhesive failures and other groups were mixed failures. This can be attributed to the adhesive debonding of synthetic diamond abrasives between titanium surface and composite resin.

Within the limitations on this study, the following conclusions were drawn. The effects of cyclic mechanical and thermal loading on the bond strength were not investigated in the present study. This limitation should be addressed in further studies, which should evaluate the effects of these parameters. Also alternative nanosurface treatment methods can be evaluated.

\section{Conclusion}

Although Silano-Pen application after air abrasion with synthetic diamond abrasives effected the bond strength of titanium to composite, there was not any difference from only air abraded surface treatment. For easy handling in clinical and laboratory conditions, Silano-pen application might improve bond strength of titanium alloy and filler particulate composite.

\section{References}

1. Walter M, Reppel PD, Böning K, Freesmeyer WB (1999) Six-year follow-up of titanium and high-gold porcelain-fused-to-metal fixed partial dentures. J Oral Rehabil 26(2): 91-96.

2. Yanagida H, Matsumura H, Taira Y, Atsuta M, Shimoe S (2002) Adhesive bonding of composite material to

Cengiz S, et al. Effect of Air Abrasion and Different Silicoating Techniques on the Bond Strength of Particulate Filler Composite to Titanium. J Dental Sci 2017, 2(3): 000139. cast titanium with varying surface preparations. J Oral Rehabil 29(2): 121-126.

3. Ban S, Taniki T, Sato H, Kono H, Iwaya Y, et al. (2006) Acid etching of titanium for bonding with veneering composite resins. Dent Mater J 25(2): 382-390.

4. Soares da Rocha S, Adabo GL, Spinola SG, Fonseca RG, Ferreira AR (2007) Effect of metal conditioners on the adhesive bonding of resin cements to cast titanium. Quint Int 38(8): 506-510.

5. Schneider R, Goes MF, Henriques GEP, Chan DCN (2007) Tensile bond strength of dual curing resinbased cements to commercially pure titanium. Dent Mater 23: 81-87.

6. Barbosa SH, Andreatta FOD, Bottino MA (2008) Durability of bond strength between titanium alloy and resin cement. Cienc Odontol Bras 11(1): 13-18.

7. Fawzy AS, El-Askary FS (2009) Effect acidic and alkaline/heat treatments on the bond strength of different luting cements to commercially pure titanium. J Dent 37(4): 255-263.

8. Fernandes CA, Ribeiro JC, Larson BS, Bonfante EA, Silva NR, et al. (2009) Microtensile bond strength of resin-based composites to Ti-6Al-4V. Dent Mater 25(5): 655-661.

9. Galo R, Riberio RC, Rodrigues RCS, Pagnano VO, Mattos MGC (2009) Effect of laser welding on the titanium composite tensile bond strength. Braz Dent J 20(5): 403-409.

10. Behr M, Rosentritt M, Gröger G, Handel G (2003) Adhesive bond of veneering composites on various metal surfaces using silicoating, titanium-coating or functional monomers. J Dent 31(1): 33-42.

11. Taira Y, Yang L, Atsuta M (2006) Comparison of four fluoride etchants in bonding between titanium and a self-curing luting agent. Dent Mater J 25(2): 345-351.

12. Faria AC, de Matos RL, Rodrigues RC, Antunes RP, Ribeiro RF, et al. (2008) Comparative study of chemical and mechanical retentive systems for bonding of indirect composite resin to commercially pure titanium. Braz Dent J 19(2): 134-138.

13. Janda R, Roulet JF, Latta M, Damerau G (2007) Spark erosion as a metal-resin bonding system. Dent Mater 23(2): 193-197. 
14. Taira Y, Odatsu T, Sawase T (2013) Effects of a fluoride etchant and a phosphate primer on bonding of veneering composite to Ti-6Al-4V alloy for CAD/CAM restorations. J Prosthodont Res 57(1): 3035.

15. Lung CY, Liu D, Matinlinna JP (2014) Surface treatment of titanium by a polydimethylsiloxane coating on bond strength of resin to titanium. J Mech Behav Biomed Mater 41: 168-176.

16. Sen D, Poyrazoglu E, Tuncelli B, Göller G (2000) Shear bond strength of resin luting cement to glassinfiltrated porous aluminum oxide cores. J Prosthet Dent 83(2): 210-215.
17. Kulunk S, Kulunk T, Ural C, Kurt M, Baba S (2011) Effect of air abrasion particles on the bond strength of adhesive resin cement to zirconia core. Acta Odontol Scand 69(2): 88-94.

18. Kulunk T, Kurt M, Ural C, Kulunk S, Baba S (2011) Effect of different air-abrasion particles on metalceramic bond strength. J Dent Sci 6(3): 140-146.

19. Marinescu ID, Uhmann E, Doi T (2007) Handbook of lapping and polishing. CRC Press: USA, pp.104, 31.

20. Kurt M, Külünk T, Ural Ç, Külünk Ş, Danişman Ş, et al. (2013) The effect of different surface treatments on cement-retained implant-supported restorations. J Oral Implantol 39(1): 44-51. 